\title{
EcoCTD for Profiling Oceanic Physical-Biological Properties from an Underway Ship
}

\author{
Woods Hole Oceanographic Institution, Woods Hole, Massachusetts \\ ANDREW J. BARON \\ Dynamic System Analysis, Halifax, Nova Scotia, Canada \\ Amala MaHADEVAN \\ Woods Hole Oceanographic Institution, Woods Hole, Massachusetts
}

Mathieu Dever, Mara Freilich, J. Thomas Farrar, Benjamin Hodges, and Tom Lanagan

(Manuscript received 29 August 2019, in final form 2 March 2020)

\begin{abstract}
The study of ocean dynamics and biophysical variability at submesoscales of $O(1) \mathrm{km}$ and $O(1) \mathrm{h}$ raises several observational challenges. To address these by underway sampling, we recently developed a towed profiler called the EcoCTD, capable of concurrently measuring both hydrographic and bio-optical properties such as oxygen, chlorophyll fluorescence, and optical backscatter. The EcoCTD presents an attractive alternative to currently used towed platforms due to its light footprint, versatility in the field, and ease of deployment and recovery without cranes or heavy-duty winches. We demonstrate its use for gathering highquality data at submesoscale spatiotemporal resolution. A dataset of bio-optical and hydrographic properties, collected with the EcoCTD during field trials in 2018, highlights its scientific potential for the study of physical-biological interactions at submesoscales.
\end{abstract}

\section{Introduction}

There is growing interest in observing the vertical structure of the ocean on horizontal scales less than $10 \mathrm{~km}$ to characterize the variability associated with meso- and submesoscale eddies and fronts. The traditional CTD rosette, a workhorse for observational oceanography, requires the ship to stop and hold station, forcing a compromise between the number and the synopticity of observations. Sampling the vertical structure of the upper ocean synoptically at order $1 \mathrm{~m}$ spacing in the vertical, and $1 \mathrm{~km}$ in the horizontal, has become possible due to the development of instruments for profiling the ocean while the ship is underway. These technologies offer the scope to explore the ocean at a horizontal resolution that reveals a wealth of structure and variability that we are only beginning to understand (e.g., Jaeger et al. 2019, manuscript submitted to J. Phys. Oceanogr.; Shroyer et al. 2019). While gliders and other autonomous instrument platform have revolutionized observational oceanography

\footnotetext{
Corresponding author: Mathieu Dever, mdever@whoi.edu
}

and offer some of the most cost-effective ways for sustained profiling of the ocean, they are relatively slow. Ship-based profiling is more rapid, less severely affected by space-time aliasing, and more flexible for planning adaptive sampling strategies or opportunistically making use of ship transits. Here, we discuss a variant of previously used methods of ship-based profiling.

The many different instruments and sampling platforms developed for underway profiling from a ship can be organized into two categories: free-falling profilers and towed vehicles. A hallmark of the first category is the expendable bathythermograph (XBT) instrument, capable of free-falling through the water column to measure temperature while the ship is underway. More recently developed free-falling profilers are now tethered to the ship to allow recovery, and include CTD sensors measuring conductivity, temperature, and pressure. These profilers are usually released to free-fall vertically through the water column, and collect a vertical profile at the release location. Once the downcast is completed, the profiler is reeled back to the ship using a winch, and released again to collect another profile (Rudnick and Klinke 2007; Pinkel et al. 2012). 
This method of repeated profiling while underway is capable of providing a relatively small spatial and temporal spacing between profiles that mostly depends on the ship's speed and the time required to complete the profile. Several probes were developed to collect accurate and reliable observations using free-falling profilers. The Underway CTD developed by Rudnick and Klinke (2007) and made commercially available by Teledyne Oceanscience is a widely used profiler, for which data processing has been improved through several studies (e.g., Ullman and Hebert 2014). Other successfully used profilers include the Moving Vessel Profiler (AML Oceanographic; Furlong et al. 2006) and the FastCTD (Rajagopalan 2019; licensed to Valeport). Most of these free-falling probes traditionally focus on measuring conductivity, temperature, and pressure, although the addition of a fluorometer and other sensors is under development. They rely on winch systems, which range from lightweight, manually operated winches with intermittent data download, to fully automated winch systems, with real-time data recovery as in the case of the FastCTD.

The second category is composed of larger towed vehicles that have the advantage of being highly modular in their payload, accommodating sensors based on user-specific needs, and often offering real-time data on board the ship. Some widely used platforms include the SeaSoar (Chelsea Technologies Group Ltd.; Pollard 1986), the Scanfish (EIVA; Brown et al. 1997), the Triaxus (MacArtney Underwater Technology; D'Asaro et al. 2011; Jones et al. 2011), and the more recently developed Wire Flyer (Roman et al. 2019). These towed vehicles are usually more costly than free-falling profilers, and rely on a crane or A-frame for deployment and recovery, as well as a heavy duty winch for towing.

Submesoscale fronts and instabilities (McWilliams 2019), have a substantial impact on upper-ocean stratification, biogeochemical distributions and fluxes, phytoplankton productivity, and the transport of organically produced carbon and oxygen from the euphotic layer (Mahadevan 2016). The distributions of biological properties (which can change on time scales on the order of 1 day) in response to submesoscale physical transport, which occurs on time scales on the order of a day, is particularly important to measure and assess. Conversely, biological tracers, such as oxygen and chlorophyll fluorescence, can be used to identify physical features as demonstrated in Omand et al. (2015), where glider data were used to identify physical processes during the North Atlantic Bloom (NAB) experiment. The potential to exploit concurrent measurements of physical and biological properties and explore physical-biological interactions at submesoscales has energized an effort to measure proxies for biogeochemical properties and processes (such as dissolved oxygen, chlorophyll fluorescence and optical backscatter) along with the hydrography.

To address the rising need for concurrent biophysical observations at spatiotemporal resolutions capturing submesoscales, we developed a lightweight, highly versatile, modular profiler called the EcoCTD. This instrument builds on the well-established Underway CTD system (Rudnick and Klinke 2007), by replacing the Underway CTD (UCTD) probe with the EcoCTD, which combines a CTD, oxygen sensor, and bio-optical sensor measuring fluorescence and backscatter.

The EcoCTD was developed as part of the Coherent Lagrangian Pathways from the Surface Ocean to Interior (CALYPSO) Departmental Research Initiative funded by the U.S. Office of Naval Research. Successful field trials were conducted during cruises in the western Mediterranean Sea in May-June 2018 (Dever et al. 2019), and in March-April 2019. In section 2, we introduce the design of the EcoCTD, its key characteristics, and operation at sea. In section 3, we use data obtained during the 2018 field trial to establish the data processing steps necessary to analyze the EcoCTD dataset and provide insight on how to geolocate the EcoCTD during upcasts. We demonstrate the potential of the EcoCTD by presenting some of the data obtained during the 2018 sea trial. In section 4 we summarize the key features and discuss future developments that will be applied to subsequent versions of the EcoCTD.

\section{The EcoCTD probe}

\section{a. Probe design}

The EcoCTD probe is composed of three main instruments: 1) an RBR Concerto ${ }^{3}$ measuring conductivity, temperature, and pressure, that also acts as a datalogger, 2) a JFE-Advantech Rinko III measuring dissolved oxygen saturation, and 3) a Sea-Bird Scientific WetLabs BB2F ECOPuck measuring backscatter at two wavelengths (470 and $700 \mathrm{~nm}$ ), as well as fluorescence (Fig. 1). These three instruments are encased in a specially designed housing that consists of a $0.9 \mathrm{~m}$ long aluminum tube with a $10 \mathrm{~cm}$ outer diameter. At the top-end of the tube, a mechanical coupling is installed to allow the EcoCTD to be attached to the UCTD tail spool (Fig. 1a). This design enables the EcoCTD to be deployed from the UCTD machinery and be used interchangeably with the UCTD probe without any alternate fastening or splicing of the line, thereby increasing versatility without increasing the risk of instrument loss. At the lower end of the tube, two weight collars weighing between 2.2 and $2.5 \mathrm{~kg}$ are installed to ensure 1) an optimal fall rate, and 2) the 

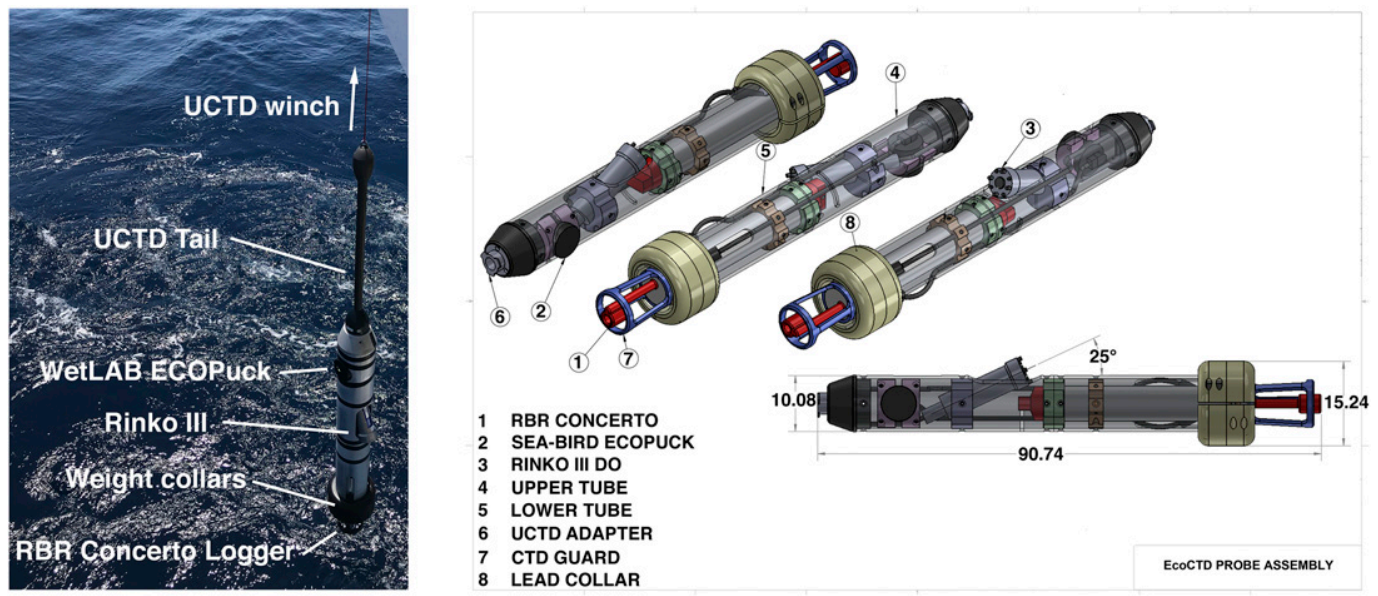

FIG. 1. (left) EcoCTD probe being deployed from the NRV Alliance during a 2018 cruise in the Alboran Sea. (right) Engineering drawing of the EcoCTD design depicting the CTD the key components of the probe. Dimensions are in centimeters unless mentioned otherwise.

orientation of the probe as it falls through the water column with the lower end facing the direction of the flow. The edges of the weight collars are tapered to decrease the form drag of the EcoCTD while free-falling. The housing is designed to flood with water and includes several openings to evacuate trapped air bubbles that could affect the probe fall rate. When assembled, the dry weight of the EcoCTD is $12.49 \pm 0.01 \mathrm{~kg}$. The EcoCTD's density is estimated to be $2841.60 \mathrm{~kg} \mathrm{~m}^{-3}$ from weighing the assembled instrument while submerged in a saltwater tank $\left(\rho_{\text {tank }}=1023.794 \mathrm{~kg} \mathrm{~m}^{-3}\right)$.

Sensors are arranged to maximize data quality while profiling: The CTD head points in the direction of the flow when free-falling, guaranteeing a good rate of water flow through the sensors while profiling (Fig. 1b). The oxygen sensor is located $48 \mathrm{~cm}$ away from the CTD head and is facing downward at an angle of $25^{\circ}$ from the vertical. The residence time of a water parcel at the oxygen sensor is safely assumed to be much shorter than the response time of the sensor (approximately $1 \mathrm{~s}$; see section $2 \mathrm{~b}$ ). The ECOPuck is located $72 \mathrm{~cm}$ away from the CTD head and oriented horizontally, at $90^{\circ}$ to the axis of the housing tube.

\section{b. Sensor characteristics}

All instruments sample at $8 \mathrm{~Hz}$ frequency. Measurements are stored internally within the RBR Concerto ${ }^{3}$ logger. On the Concerto ${ }^{3}$, conductivity is measured inductively by measuring the change in ionic current between a drive coil generating the current and a receiving coil. This change in ionic current is directly related to the conductance of the liquid present in the center of the coils. The inductive conductivity sensor is encased in plastic, which prevents corrosion. Inductive conductivity measurements are sensitive to any material in the proximity of the sensor. In the case of the EcoCTD, the addition of a plastic guard for protecting the CTD head (see Fig. 1) postcalibration generated an offset in conductivity measurements. As a results, crosscalibration casts were completed during sea trials, where the EcoCTD was mounted onto a shipboard CTD rosette (see section 3 ).

The Rinko III determines dissolved oxygen by measuring the phosphorescence life or quenching time of phosphorescence, which is a function of oxygen partial pressure in the water. High oxygen saturation supports a greater phosphorescence intensity and longer phosphorescence life. Using this optical technique presents the advantage that oxygen saturation is not sensible to biofouling, ensuring longer measurement stability, and does not require stirring, as no oxygen molecules are consumed in the process (Bittig et al. 2014). Oxygen saturation is a function of temperature and is computed on board the Rinko instrument using the temperature sensor located on the Rinko. Using the Rinko's temperature instead of the CTD temperature decreases the accuracy of the oxygen saturation due a lower sensor precision, but presents the advantage that the Rinko oxygen and temperature sensors are next to each other. Unfortunately, due to instrument integration constraints with the Concerto ${ }^{3}$ logger, temperature measurements from the Rinko were not logged (see technical improvements in section 4).

Backscatter at 470 and $700 \mathrm{~nm}$, as well as fluorescence, are measured from a Sea-Bird Scientific WetLabs ECOPuck sensor and logged by the RBR Concerto ${ }^{3}$. Each of these optical variables are measured in counts and can be converted to scattering (in $\mathrm{s}^{-1} \mathrm{sr}^{-1}$ ) or chlorophyll-a concentration (in $\mu \mathrm{gL}^{-1}$ ) using linear 
TABLE 1. Characteristics of sensors mounted on the EcoCTD $(\mathrm{FS}=$ full scale $)$.

\begin{tabular}{lccc}
\hline \hline \multicolumn{1}{c}{ Variable } & Range & Resolution & Accuracy \\
\hline Conductivity & $0-85 \mathrm{mS} \mathrm{cm}^{-1}$ & $0.001 \mathrm{mS} \mathrm{cm}^{-1}$ & $\pm 0.003 \mathrm{mS} \mathrm{cm}^{-1}$ \\
Temperature & $-5^{\circ}-35^{\circ} \mathrm{C}$ & $0.00005^{\circ} \mathrm{C}$ & $\pm 0.002^{\circ} \mathrm{C}$ \\
Pressure & $0-750 \mathrm{dbar}$ & $0.001 \% \mathrm{FS}$ & $\pm 0.05 \% \mathrm{FS}$ \\
Dissolved oxygen & $0 \%-200 \%$ & $0.01 \%-0.04 \%$ & $\pm 2.00 \%$ \\
Chlorophyll & $0-50 \mu \mathrm{g} \mathrm{L}^{-1}$ & $0.0045 \mu \mathrm{g} \mathrm{L}^{-1}$ & $\pm 0.0121 \mu \mathrm{g} \mathrm{L}^{-1}$ \\
Backscatter & $0-4121$ counts & $1.00 \mathrm{count}$ & $\pm 0.58 \mathrm{count}$ \\
\hline
\end{tabular}

relationships derived from discrete sampling. Although those three channels were selected based on specific scientific objectives, other channels could be selected for the ECOPuck (e.g., rhodamine fluorescence, fluorescent dissolved organic matter). Characteristics (range, accuracy, and precision) of the different sensors are listed in Table 1.

\section{c. Modus operandi}

UCTD probes can be deployed in two different configurations (Rudnick and Klinke 2007): In "free-cast" mode, the line is spooled around the UCTD tail spool and the UCTD probe is dropped from the height of the ship's freeboard. In this mode, the probe is assumed to be decoupled from the ship's motion (e.g., from surface waves) and tends to free-fall with a consistent fall rate. In "tow-yo" mode the probe is dropped in the water with no line on the UCTD tail spool and unspools line from the freely rotating winch as it falls through the water. Once the profile is completed, the probe is reeled back toward the ship and can be released for the next profile as soon as it is close to the vessel's stern. The main advantage of operating in tow-yo mode is the omission of the spooling time, which reduces the time between profiles and results in a higher lateral resolution. However, the fall rate of the probe becomes sensitive to the line drag, and therefore decreases exponentially with depth (Fig. 2c; Rudnick and Klinke 2007; Ullman and Hebert 2014).

During sea trials, the EcoCTD was exclusively operated in tow-yo mode. It was slowly lowered to the ocean surface to start a series of casts in tow-yo mode, as opposed to being repeatedly dropped from the height of ship's stern. The EcoCTD is considerably heavier than the UCTD probe and the exposed CTD head of the EcoCTD may not be able to endure repeated hits on the water surface when dropped from the ship's freeboard height in free-cast mode. However, it is expected that the EcoCTD is not as sensitive to line drag as the UCTD probe, due to its larger mass (12.5 vs $3.6 \mathrm{~kg}$ ).

For each deployment, the EcoCTD was therefore connected to the UCTD tail spool and slowly lowered to the water surface before being released to free-fall vertically through the water column for a specific amount of time set by the target profile depth. The probe was then reeled back to the ship at $0.5-2 \mathrm{~m} \mathrm{~s}^{-1}$, speeding up with time as the diameter of the drum increases with more line. Once the EcoCTD was brought within a few meters from the ship's stern, the probe was released once again to complete another profile. Typically, profiles were measured to a depth of 200-300 m, which corresponds to a free-falling time between 50 and $100 \mathrm{~s}$, and were separated in time by 4-7 min. The ship's speed through water during EcoCTD deployment ranged between 4 and $9 \mathrm{kt}\left(1 \mathrm{kt} \approx 0.51 \mathrm{~m} \mathrm{~s}^{-1}\right)$. Large line tension and slight overheating of the winch motor were experienced at speeds above $8 \mathrm{kt}$.

Once a significant amount of profiles were collected (usually 10), the EcoCTD probe was recovered on board the ship. Data were downloaded through Wi-Fi or a cabled connection and wiped from the instrument. This mode of operation limits data loss in case of probe loss and keeps data downloading time to a minimum.

Measurements are collected on downcasts, where the EcoCTD is assumed to be free-falling vertically (appendix B), as well as upcasts, while the probe is being reeled back to the ship. On downcasts, the orientation of all instruments guarantees a good water flow over the sensors. On upcasts, however, the quality of CTD and oxygen measurements is highly degraded as the instruments are sampling in the wake of the EcoCTD and mostly measure turbulent motions associated with the EcoCTD being reeled back to the ship. In section 3b, we demonstrate that the EcoCTD collects high-quality biooptical data on upcasts. The vertical resolution of the data depends on the fall rate of the EcoCTD, and ranges between $0.25 \mathrm{~m}\left(2 \mathrm{~m} \mathrm{~s}^{-1}\right.$ fall rate $)$ and $0.5 \mathrm{~m}\left(4 \mathrm{~m} \mathrm{~s}^{-1}\right.$ fall rate; Fig. 2). The lateral resolution depends exclusively on the ship's speed and the time it takes to complete a profile (downcast and upcast), which is affected by the depth of the profile. During our sea trial, typical profile duration was about $4 \mathrm{~min}$ for $200 \mathrm{~m}$ deep profiles, and $6 \mathrm{~min}$ for $300 \mathrm{~m}$ deep profiles (see example profile in Fig. 2a). Profiles were collected at a ship speed ranging from 3 to $8 \mathrm{kt}$, leading to a profile separation ranging between 450 and $1000 \mathrm{~m}$. Additional field tests were 

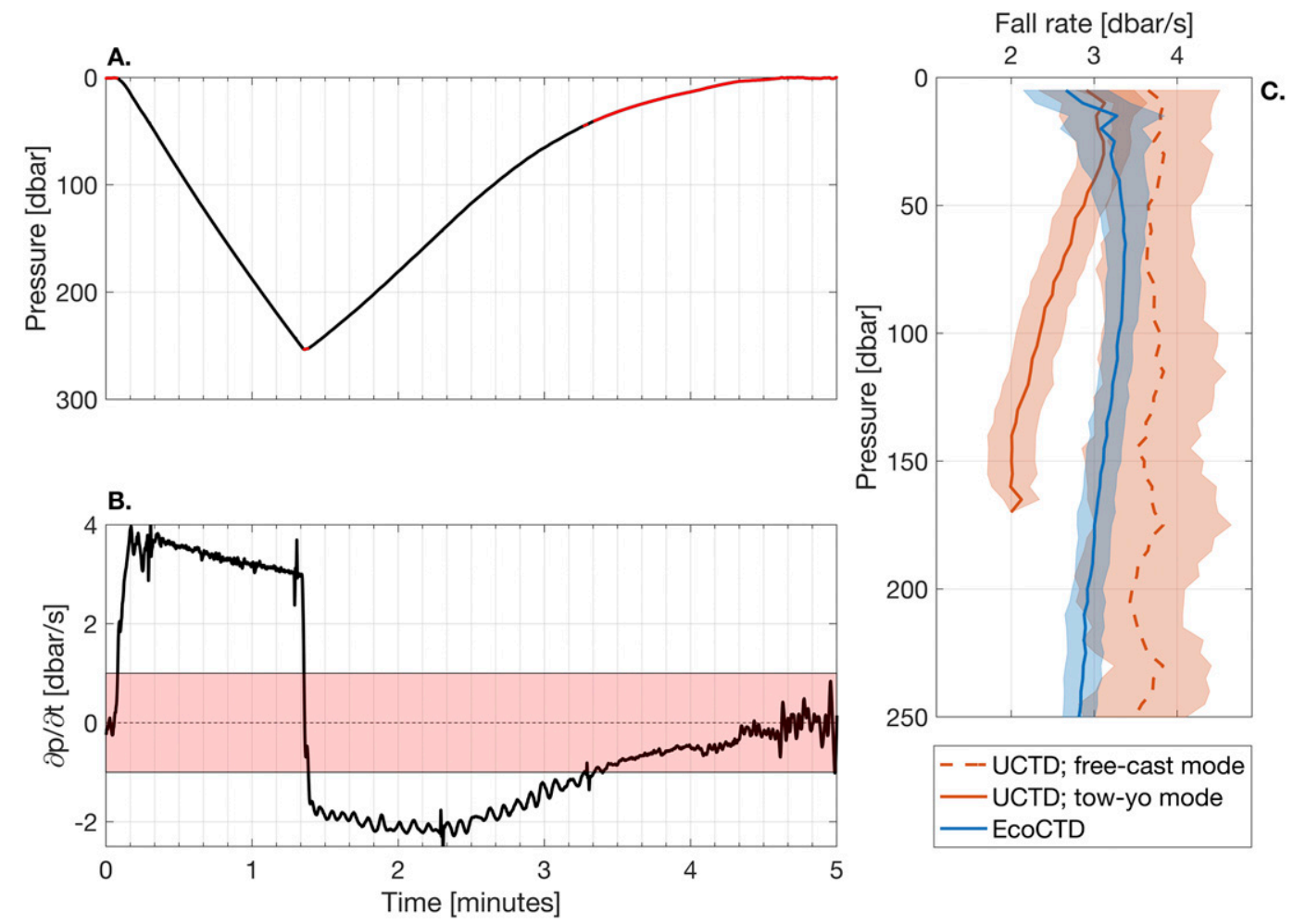

FIG. 2. (a) Pressure (dbar) as a function of time (min) for an example profile collected on 28 May 2018. Data points recorded at a fall rate of less than $1 \mathrm{dbar} \mathrm{s}^{-1}$ are shown in red. (b) Fall rate (dbar s${ }^{-1}$ ) as a function of time. The red shaded region shows fall rates slower than $1 \mathrm{dbars}^{-1}$. Positive (negative) fall rates correspond to the downcast (upcasts). (c) Fall rate as a function of pressure on downcast only. Fall rates were averaged over all UCTD profiles collected in free-cast mode (dashed red; $N=114$ ), in tow-yo mode (solid red; $N=273$ ), and for EcoCTD profiles reaching $250 \mathrm{~m}$ or deeper (blue; $N=223$ ). Thick lines represent the average fall rate, while the shading shows one standard deviation from the mean.

later conducted to better predict the lateral temporal and spatial resolution between profiles for a wide range of profile depth and ship speed (Fig. 3).

\section{d. Performance comparison with the Underway CTD}

Profiling performance of the EcoCTD is compared to UCTD profiling characteristics in both tow-yo and freecast modes. The depth dependency of the fall rate is examined for both probes using UCTD profiles conducted in free-cast mode to depths greater than $250 \mathrm{~m}$ $(N=114)$, along with UCTD profiles conducted in towyo mode to a depth of at least $150 \mathrm{~m}(N=273)$. These are compared with EcoCTD profiles to depths greater than $250 \mathrm{~m}(N=223$; Fig. $2 \mathrm{c})$.

UCTD profiling characteristics vary between the two deployment modes. In free-cast mode, the average freefall rate is $3.7 \mathrm{dbar} \mathrm{s}^{-1}\left(\sigma=0.7 \mathrm{dbar} \mathrm{s}^{-1}\right)$ and is relatively consistent over the $250 \mathrm{~m}$ depth range. In tow-yo mode, however, the average fall rate of the UCTD probe decreases from 3 to $2 \mathrm{dbars}^{-1}$ over the first $150 \mathrm{~m}$. This decrease in fall rate in tow-yo mode is explained by the relatively light weight of the UCTD probe, making it particularly sensitive to line drag.

The larger mass of the EcoCTD probe has some advantages that result in higher-quality data at a higher spatial resolution possible in tow-yo mode. First, the mass guarantees an average fall rate of approximately $3 \mathrm{dbars}^{-1}$, which is comparable to the UCTD probe in free-cast mode (Fig. 2c). This is an important requirement to maintain sufficient water flow past the different sensors. Second, greater momentum of the falling EcoCTD makes the fall rate less sensitive to other motions such as surface waves or ship's motion (appendix B). The standard deviation of the fall rate for the EcoCTD is thus smaller than for the UCTD ( 0.25 and $0.65 \mathrm{dbars}^{-1}$, respectively; see Fig. 2c). Third, it makes the EcoCTD less sensitive to line drag, as shown by the smaller depth dependency of the fall rate for the EcoCTD (Fig. 2). When both EcoCTD and UCTD are operated in tow-yo mode, the UCTD experiences a slowdown of $0.8 \mathrm{dbars}^{-1}$ $(100 \mathrm{~m})^{-1}$, while the EcoCTD experiences an average 

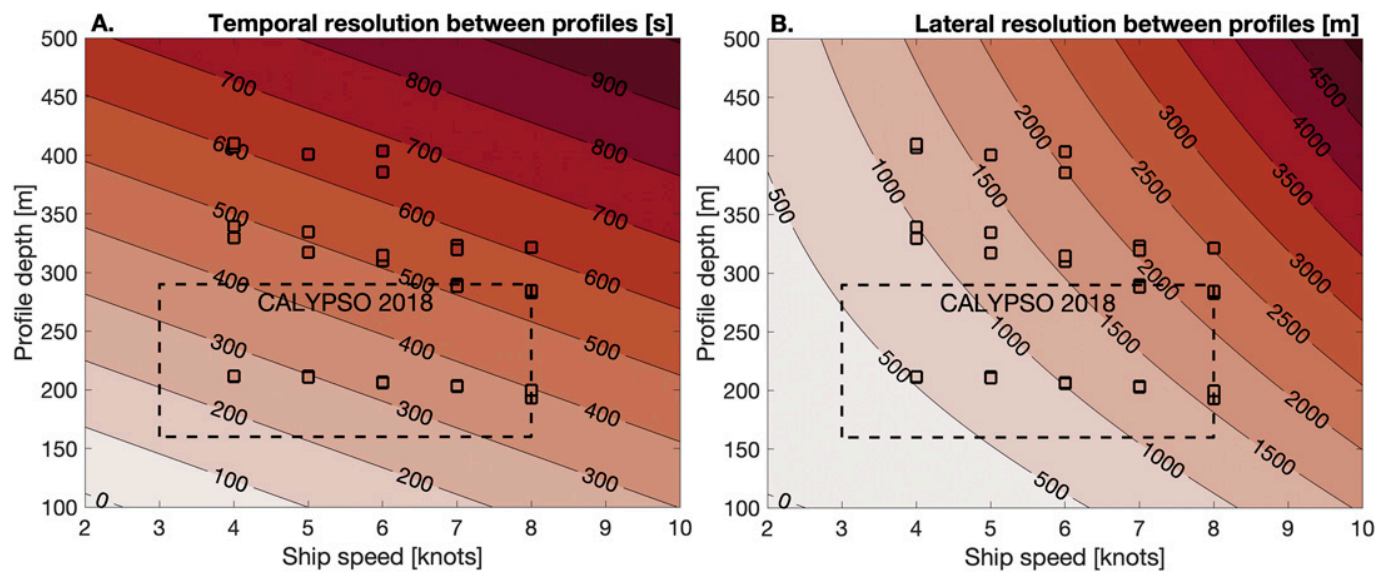

FIG. 3. Estimated lateral (a) temporal and (b) spatial resolution as a function of both ship speed over ground and profile depth, based on field tests (squares). A black dashed box is superimposed to indicate the typical operating conditions during the CALYPSO cruise in 2018 (see section 3).

slowdown of $0.3 \mathrm{dbars}^{-1}(100 \mathrm{~m})^{-1}$. However, the EcoCTD's larger mass and form drag leads to a longer initial period of acceleration over the first $50 \mathrm{dbar}$ of the water column (appendix B).

\section{Field results}

Sea trials were conducted aboard the NATO Research Vessel (NRV) Alliance in the Alboran Sea in June 2018 as part of the CALYPSO Program. The main objective of the field campaign was to unravel the three-dimensional coherent pathways by which water parcels are transported from the surface ocean to depths below the mixed layer. The EcoCTD was deployed to profile the water column repeatedly at a horizontal spacing of $1-2 \mathrm{~km}$ across a sharp density front, with the aim of characterizing water mass subduction from the ocean mixed layer to ocean interior as was previously observed in this region by an ocean glider (Ruiz et al. 2009).

\section{a. Sensor processing}

\section{1) Sensor ALignment}

\section{(i) CTD sensor}

Misalignment of temperature and conductivity measurements results in spikes in computed salinity, because conductivity is temperature dependent (Fig. 4). This misalignment emerges from the sensors' different response times, and is routinely corrected when processing UCTD data (Ullman and Hebert 2014). There are a number of differences between the EcoCTD and UCTD probes, including the physical arrangement of the temperature and conductivity sensors, data-logging frequency, and fall rate that necessitate slight differences in the processing of the EcoCTD and UCTD data. We determined the appropriate lag for the EcoCTD data empirically using the methodology of Barth et al. (1996), which relies on the correlation between temperature and conductivity. The lag was thus determined as the number of scans for which the first-difference conductivity $\left(\Delta C=C_{t}-C_{t-1}\right)$ and temperature $\left(\Delta T=T_{t}\right.$ $\left.T_{t-1}\right)$ had the maximum correlation. To find the correlations, each profile was divided into nonoverlapping 60 scan $(7.5 \mathrm{~s})$ segments. Fractional values of the lag were found by fitting a second-order polynomial around the

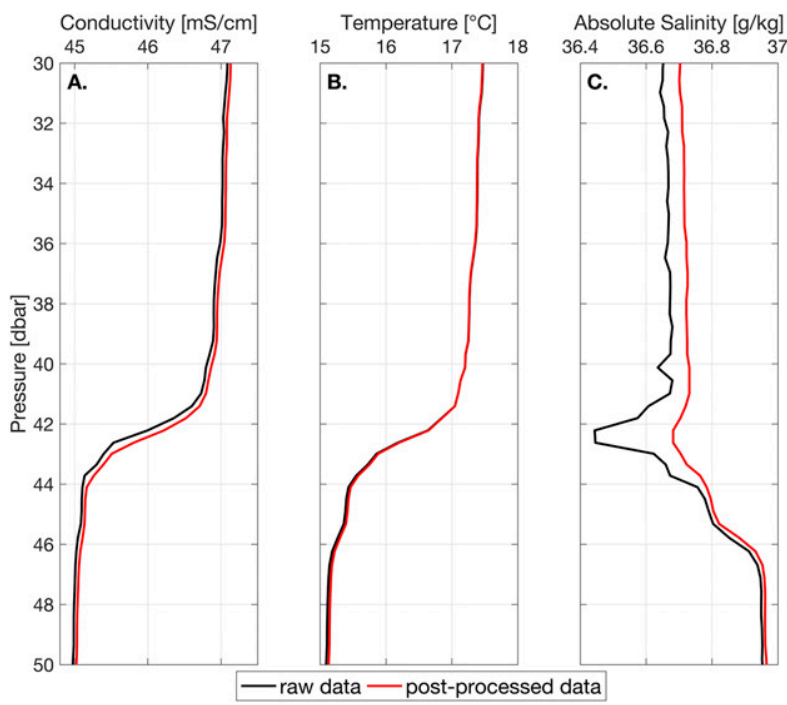

FIG. 4. (c) Example of an artificial salinity spike present in the raw data (black line) for measurement collected in the same profile as the one shown in Fig. 2. Salinity spiking is generated by the misalignment of the sensors measuring (a) conductivity and (b) temperature. During postprocessing, a response lag of 0.5 scans is applied to the conductivity to minimize salinity spiking (red line). 
maximum integer value of lag correlation and finding the maximum of that function, as described in Ullman and Hebert (2014). We found that the maximum correlation is between zero and one scan for $70 \%$ of the data segments. For the remaining $30 \%$ of the segments, the misalignment of the temperature and conductivity measurements was not the dominant signal. In contrast to the results of Ullman and Hebert (2014), we did not find a relationship between drop rate and lag, and thus used a constant value of lag for all profiles. Empirically, we found that a lag of 0.5 scans minimizes the salinity spiking (Fig. 4). We apply the lag by interpolating the conductivity data onto a shifted time axis, which results in a slight smoothing of the conductivity profile.

\section{(ii) Oxygen sensor}

Misalignment between the oxygen sensor and the CTD measurements occurs because of the physical separation of the oxygen sensor from the CTD and because the oxygen sensor has a slower response time than the CTD. Properly aligning observations collected for the two instruments is crucial, as dissolved oxygen concentration is temperature, and salinity, dependent.

The lag introduced by the physical separation between the two sensors depends on the fall rate of the probe and is thus referred to as "advective lag." The advective lag can be computed using the following equation:

$$
\Delta S_{\mathrm{adv}}=\frac{\Delta h F_{s}}{w_{s}},
$$

where $\Delta S_{\text {adv }}$ is the lag in number of scans, $\Delta h$ is the distance between the two sensors $(48 \mathrm{~cm}), F_{s}$ is the sampling frequency $(8 \mathrm{~Hz})$, and $w_{s}$ is the fall rate computed from the ratio of first-order differences of pressure to time $(\Delta P / \Delta t)$. Advective lags are thus positive on the downcast $\left(w_{s}>0\right)$, and negative on the upcast $\left(w_{s}<\right.$ $0)$. Computed advective lags were between 0.8 and 2 scans, with $91 \%$ of the lags between 1 and 1.5 scans and a median of 1.23 scans.

In addition to the advective lag, we also consider the "response lag," which is a constant lag associated with the different response times of the two sensors. Following recommendations from Halverson et al. (2017), the appropriate response lag is determined from $T-\mathrm{O}_{2}$ curves and the necessary adjustment to "collapse" the up and down casts to a mismatch that is equivalent to the mismatch observed in temperature and conductivity profiles ( $\sim 5$ dbar; see Fig. 5 e). A lag of 6 scans $(0.75 \mathrm{~s})$ is chosen, which is slightly shorter than, but similar to, the $0.9 \mathrm{~s}$ response time of the oxygen sensor advertised by the manufacturer.
Bittig et al. (2014) also found a relationship of effective response lag to temperature and fall rate. These second-order relationships were not used when aligning the oxygen and CTD sensors. Due to the limited temperature range $\left(\sim 6^{\circ} \mathrm{C}\right)$ and consistent fall rate, the effective response time does not have a large dependence on these factors (see Figs. 5 and 6 in Bittig et al. 2014).

\section{(iii) ECOPuck sensor}

Similar to the oxygen sensor, an advective lag is applied to the measurements collected by the ECOPuck using Eq. (1) with $\Delta h=0.72 \mathrm{~m}$. Advective lags range between 1.2 and 3 scans, with $91 \%$ of the lags between 1.5 and 2.25 scans and a median of 1.85 scans.

\section{2) Filtering}

The conductivity sensor responds faster than the temperature sensor, which can result in salinity spiking at sharp temperature interfaces. To further reduce salinity spiking, a three-point median filter is applied to the conductivity signal in addition to the response lag correction.

A filter is also applied to backscatter measurements. Backscatter profiles can generally be separated into two main signals: a "baseline" signal, that captures the background profile, and a "spike signal" that contains the spikes commonly observed throughout a backscatter profile and typically attributed to larger aggregates (Briggs et al. 2011). The two signals are separated using a method similar to Briggs et al. (2011): An 11-point running minimum filter followed by an 11-point running maximum filter is applied to each profile to obtain the baseline signal. The spike signal is then used by subtracting the baseline signal from the original profile.

\section{3) CRoss CAlibration}

On both the first and last days of the cruise, a crosscalibration cast was conducted to a depth of $500 \mathrm{~m}$. The EcoCTD was mounted on the frame of the rosette, along with a Sea-Bird shipboard CTD. Measurements of temperature, conductivity and depth were collected using a Sea-Bird SBE9plus CTD. Salinity observations were corrected using a salinometer. Oxygen measurements were collected using an SBE43 dissolved oxygen sensor, and were corrected using Wrinkler analyses (Alou et al. 2018b). Finally, chl-F was measured using a Chelsea Aqua 3 fluorometer and corrected using laboratory analyses of samples during which chl-a was extracted and measured using Turner Fluorometer (Alou et al. 2018a). Observations were interpolated at $5 \mathrm{~m}$ resolution. Similarly, EcoCTD measurements were 

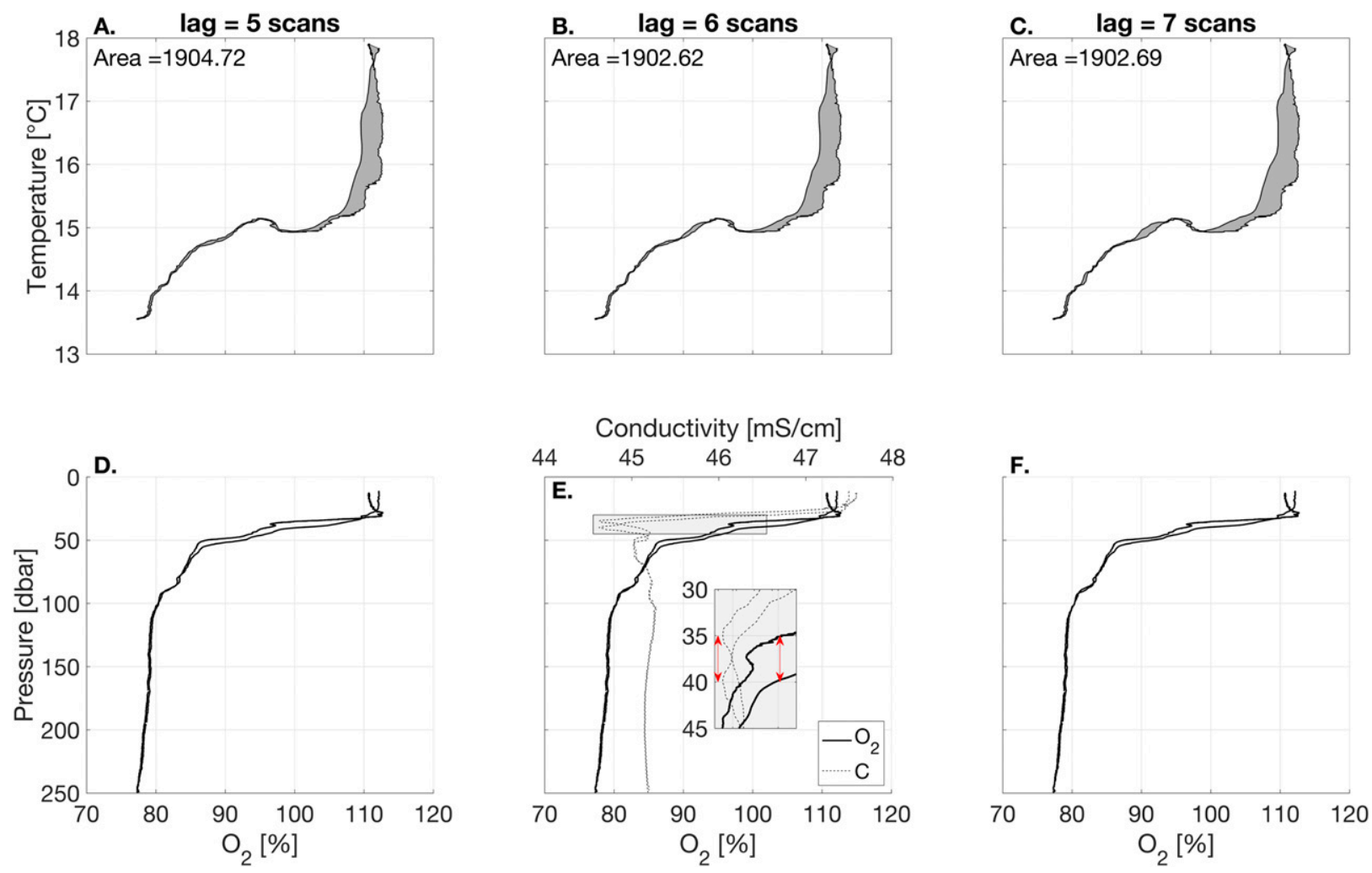

FIG. 5. Oxygen saturation profile in (a)-(c) temperature space and (d)-(f) pressure space showing both downcast and upcast for a response lag of (a),(d) 5, (b),(e) 6, and (c),(f) 7 scans. A lag of 6 scans ( 0.75 s) minimizes the difference between downcast and upcast, and yields a mismatch between downcast and upcast that is similar to the one observed in conductivity [(e); see section $3 \mathrm{a}$ and Halverson et al. (2017)].

interpolated at $5 \mathrm{~m}$ resolution for direct comparison to measurements from the shipboard CTD.

Temperature and oxygen from the EcoCTD and the ship's CTD presented a good match $\left(R^{2}=0.96\right)$ with linear regression close to the 1:1 line (Fig. 6). The offsets yielded by the regressions are both within instruments accuracy. However, there was a constant offset between the conductivity profiles of the ship's CTD and the EcoCTD. Although the RBR Concerto ${ }^{3}$ was factory calibrated before the cruise, several components were added in proximity to the conductivity cell, namely a plastic guard, a casing, and a weight (see Fig. 1). As the conductivity is measured inductively, any component located close to the conductivity cell would affect the measured ionic current, and thus the conductivity reading (Halverson et al. 2017). An offset of $0.04832 \mathrm{mS} \mathrm{cm}^{-1}$ was therefore applied to all conductivity observations to compensate for these effects (Fig. 6b).

Chl-F was measured from the shipboard CTD using a Chelsea Aqua 3 fluorometer, and calibrated using 34 samples from 17 stations. For quantification of chlorophyll-a, $0.5 \mathrm{~L}$ of seawater was filtered onto
$45 \mathrm{~mm} \mathrm{GF} / \mathrm{F}$ Whatman filters and analyzed at the Balearic Islands Coastal Observing and Forecasting System (SOCIB). Samples were extracted for $24 \mathrm{~h}$ in $90 \%$ acetone in dark conditions for fluorometric determination (Turner Designs, trilogy fluorometer; Alou et al. 2018a). A linear regression was used to convert chl-F measured from the EcoCTD in number of counts to micrograms per liter (Fig. 6d).

\section{b. Data collected on upcasts}

\section{1) Data Quality}

For free-falling profiling instruments, such as the UCTD and EcoCTD, the data quality on upcasts is traditionally thought to be poor. Sensors are mounted to face the flow while the instrument is free-falling, therefore encountering undisturbed water and maximizing data quality. During upcasts, however, sensors are measuring within the wake of the instrument. This commonly leads to a mismatch between profiles collected on the downcast and the upcast, but also to smoother upcast profiles due to the turbulent mixing generated by the instrument. 

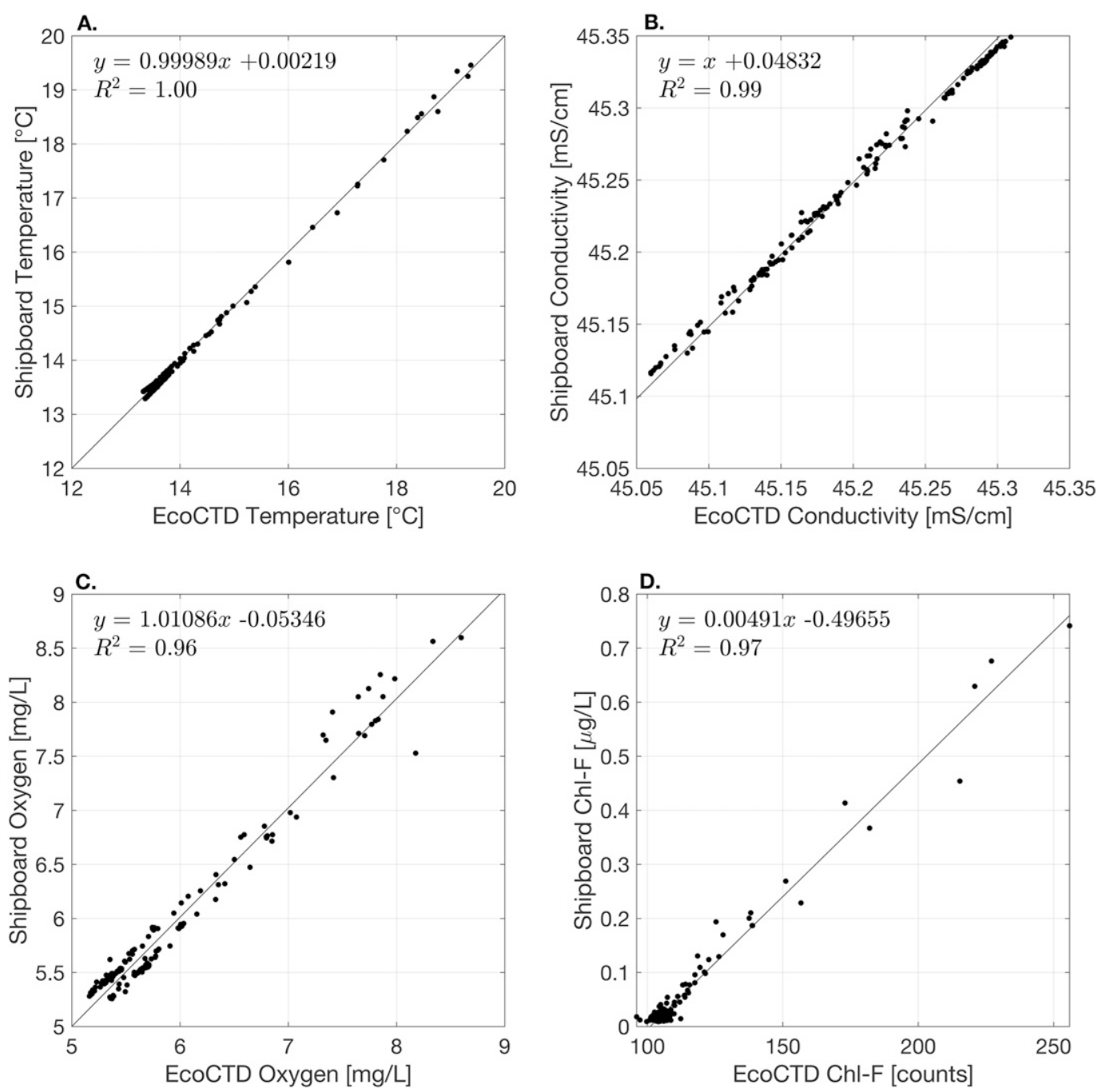

FIG. 6. Comparison between ship's CTD and EcoCTD (a) temperature, (b) conductivity, (c) oxygen concentration, and (d) chlorophyll fluorescence including both calibration casts completed on the first and last day of the cruise. Black lines show the best fit. Equation of fit and goodness of fit are indicated in each panel.

While both the CTD and oxygen sensors are oriented in a direction favorable to downcasts, the ECOPuck is oriented in the radial direction to the EcoCTD (Fig. 1), potentially making the bio-optical data usable on both down- and upcasts, increasing the spatial and temporal resolution of the data. A comparison between the data collected by the ECOPuck (backscatter and chlorophyll) on downcasts and upcasts was conducted to assess the data quality on upcasts.

To match the upcast and the downcast profiles, the following processing steps are applied: 1) the baseline signals are computed on upcast and downcast [see section $3 \mathrm{a}(2)$ ], 2) both baseline signals are binned onto a regular vertical grid, 3) the cross-correlation function is computed between the two gridded profiles to determine the lag at which the two profiles are most correlated, and 4) this corrective lag is applied to the pressure signal on the upcast. Any measurements collected at a vertical speed less than $1 \mathrm{~m} \mathrm{~s}^{-1}$ are ignored to exclude the noisy measurements collected while the EcoCTD is dragged at the ocean surface preceding a downcast and at the end of an upcast (Fig. 2a).

While there may be small-scale lateral variability, the overall shape of the down- and upcasts is expected to be correlated. The correlation between downcasts and upcasts is significantly improved after applying the corrective lag. In the case of $b_{\mathrm{bp}}$ (470), for example, the goodness of fit to a $1: 1$ line increases from $R^{2}=0.86$ to $R^{2}=0.92$. The root-mean-square-error of the upcast relative to the downcast decreases from 1.01 to 0.78 

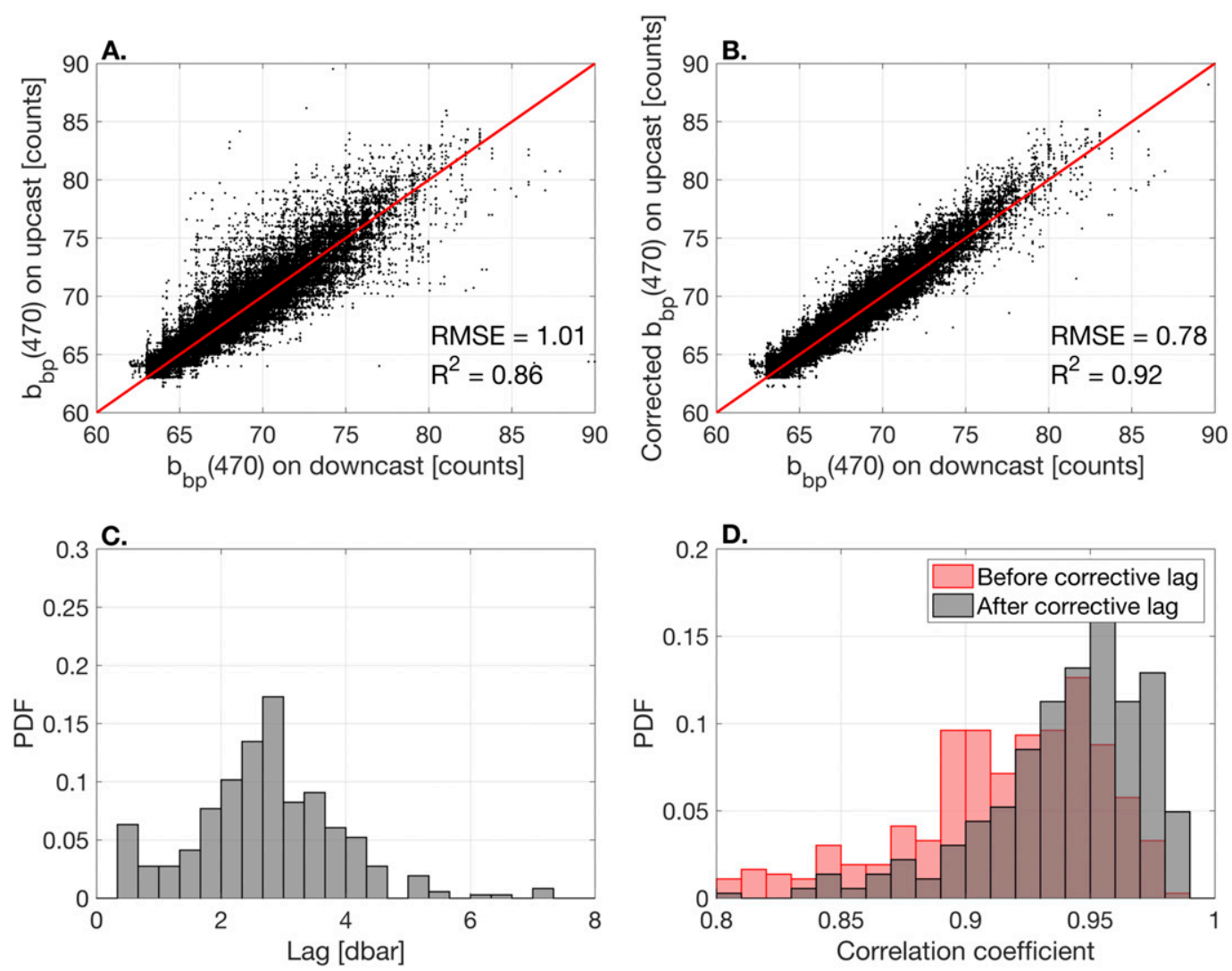

FIG. 7. Scatterplots of the baseline signal in $b_{\text {bp }}$ (470) observations (see section $3 a$ ) collected on downcasts vs upcasts (a) before and (b) after applying the corrective lag. (c) Normalized probability distribution function (PDF) of the lags used to maximize correlation. (d) PDF of the correlation coefficients between downcasts and upcasts before (red) and after (black) applying the corrective lag.

counts (Fig. 7). This result demonstrates that bio-optical data collected on upcasts are of good quality.

\section{2) UPCAST GEOLOCATION}

Our data analysis revealed that the optical data collected by the ECOPuck (backscatter and chlorophyll) on upcasts are of good quality and can be used in conjunction with the observations collected on downcasts, essentially doubling the lateral resolution. For the upcast measurements to be used in this manner, it is necessary to georeference the observations in space.

The underwater trajectory of the EcoCTD is assumed to be purely vertical on downcasts (appendix B). The spatial coordinates of the ship at the time of release thus determines the location of the downcast. On the upcast, however, the underwater trajectory of the EcoCTD is nontrivial and must be inferred (see Fig. 2). Two different approaches were considered in our analysis.

A naive approach is to apply a simple linear model by interpolating in time between the location of the downcast and the position of the ship at recovery (Fig. 8). This assumes that the EcoCTD's drag is larger than the line drag, and that the EcoCTD's trajectory is straight, resulting in a constant rate of change of pressure with time. An advantage of this simple linear model is that it does not require any knowledge of the path of the EcoCTD in the water, which is difficult to determine and is dependent on the instrument's mass, form drag, winch speed and line drag. However, time series of pressure (Fig. 2a) show that the rate of change in pressure is not constant and tends to slow down toward the end of the upcast.

To address the shortcomings of the linear model, we use a dynamical model, ProteusDS, developed by Dynamic Systems Analysis Ltd. (DSA), to simulate the EcoCTD's underwater trajectory (DSA 2018). This dynamical model relies on a finite-element line model resolving a large range of parameters (see Table A1). More information on the setup used to simulate the EcoCTD trajectory with ProteusDS is provided in appendix A. The trajectory of the EcoCTD on the upcast is subject to a "water pulley" effect, where the transverse drag of the line is significant. As a result, the EcoCTD is first pulled up vertically, with a rate of 

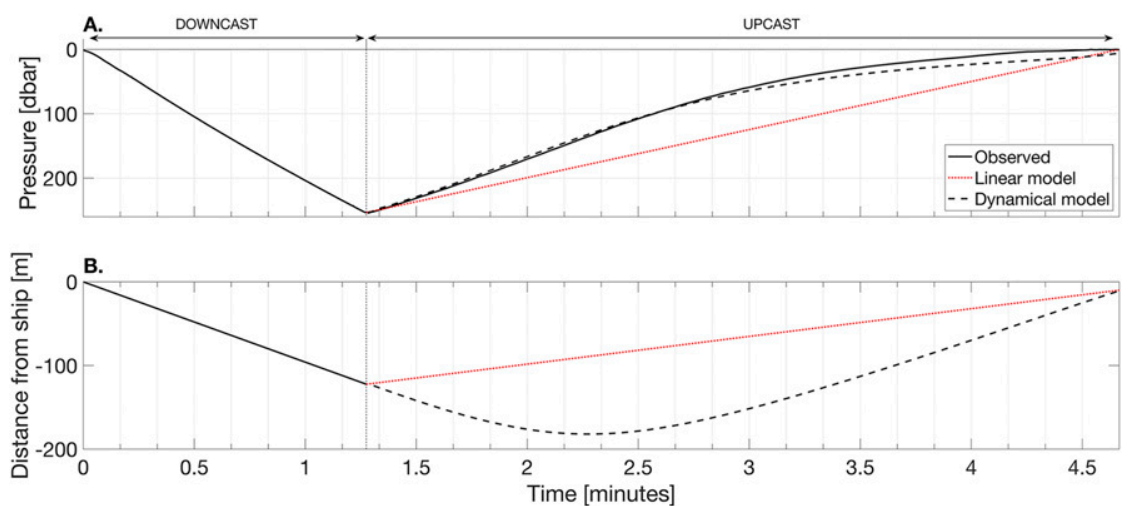

FIG. 8. (a) Time series of the pressure during the profile shown in Fig. 2a. Observed pressure (solid black) is shown along the pressure computed using the linear model (dotted red) and a dynamical model (dashed black). (b) Lateral distance between the EcoCTD and the ship. On the downcast, the distance is equal to the ship's speed multiplied by the elapsed time since release. On the upcast, the distance is either linearly interpolated in time (dotted red) or computed using a dynamical model (dashed black).

change in pressure similar to the pay in rate of the winch (Fig. 8a). As the depth of the probe decreases, the line drag weakens and the EcoCTD begins to be pulled up at an angle. Because the probe is now pulled mostly horizontally, the rate of change of pressure becomes smaller than the pay in rate of the winch.

Figure 8a shows that the dynamical model is capable of recreating the pressure signal observed by the probe on the upcast: the correlation and root-mean-square error (RMSE) between the observed pressure and the dynamical model $(r=1$, RMSE $=5.5 \mathrm{dbar})$ indicates that this dynamic model performs much better than a simple linear model $(r=0.95, \mathrm{RMSE}=53.1 \mathrm{dbar}$; see Fig. 8a). To geolocate the EcoCTD on the upcast, the horizontal distance between the ship and the probe is computed using both models (Fig. 8b). The GPS position of the ship can then be used to assign coordinates to the EcoCTD's location. Once the upcast is initiated, the EcoCTD moves mostly vertically, as shown in Fig. 8a. As a result, the distance between the EcoCTD and the ship keeps increasing at a rate matching the ship speed as the ship moves laterally while the EcoCTD only moves vertically. This is evident in the agreement in the slopes in Fig. 8b during downcast $(0-75 \mathrm{~s})$ and the beginning of the upcast (75-120s).

For the specific profile showed in Fig. 8b, the difference in the EcoCTD's location between the linear and dynamical models can be over $100 \mathrm{~m}$. This difference is significant, especially in the context of resolving submesoscales on the order of $1 \mathrm{~km}$. While the profile shown in Fig. 8 was collected at a relatively slow cruising speed of $3.2 \mathrm{kt}$, most profiles are collected at a speed between 5 and $8 \mathrm{kt}$. Higher ship speed will increase the horizontal distance covered by the ship during the first phase of the upcast where the EcoCTD rises vertically, increasing the discrepancy between linear and dynamical models.

\section{c. Sample data}

During the 2018 CALYPSO field campaign, 371 profiles were collected using the EcoCTD, covering 11 transects across the Almeria-Oran front (Dever et al. 2019). This region is characterized by a semipersistent ocean front separating the fresher water coming from the Atlantic Ocean through the Strait of Gibraltar, and the more saline Mediterranean water (Allen et al. 2001). At the time of the cruise in late spring, the water column is characterized by a warm surface layer due to net solar heating, leading to a shallow mixed layer depth $(\sim 20 \mathrm{~m}$; see Fig. 9).

The EcoCTD was deployed to collect biophysical observations of subducted water masses at submesoscales $(<10 \mathrm{~km})$ along the Almeria-Oran front (Ruiz et al. 2019). The hypotheses are that 1 ) subducted filaments are easily detectable in bio-optical variables and should correspond to the hydrographic signals, and 2) bio-optical variables can be used as a passive tracer to infer the pathway and subduction rate of the subducted water. To test these hypotheses, we traversed the Almeria-Oran Front and collected 45 profiles while the ship was underway at a speed of $7 \mathrm{kt}\left(3.6 \mathrm{~m} \mathrm{~s}^{-1}\right)$, except close to the front $\left(-2.40^{\circ}\right.$ to $\left.-2.15^{\circ}\right)$, where the ship speed was reduced to $3 \mathrm{kt}\left(1.5 \mathrm{~m} \mathrm{~s}^{-1}\right)$ to reduce the lateral spacing between profiles (See Fig. 3). Chlorophyll, oxygen saturation, and backscatter at $470 \mathrm{~nm}$ along this section are shown in Fig. 10. The vertical resolution of the EcoCTD observations is fine enough to resolve a deep chlorophyll maximum (DCM) between 30 and $60 \mathrm{~m}$ depth. In density 

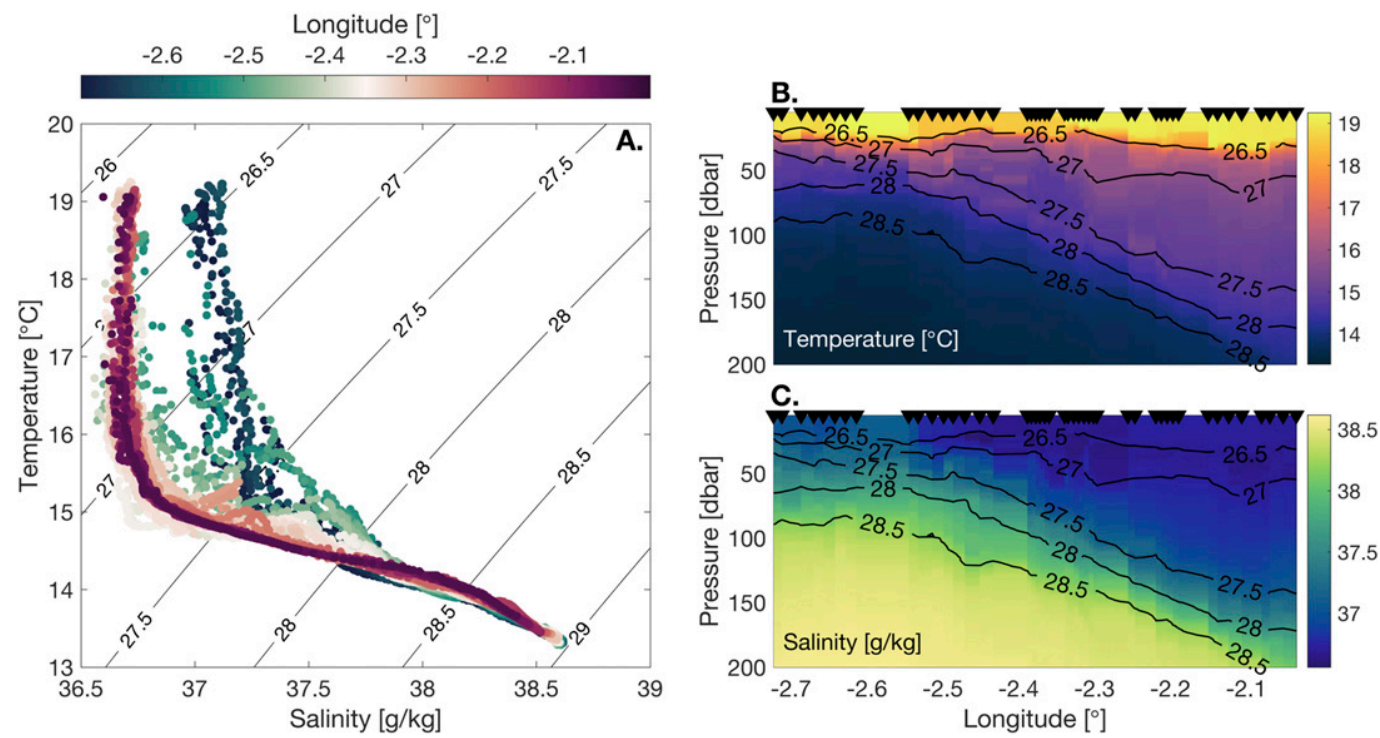

FIG. 9. (a) Temperature-salinity $(T-S)$ diagram for a section across the Almeria-Oran front in the Alboran Sea completed between 1547 UTC 29 May and 0119 UTC 30 May 2018. The $T-S$ diagram clearly shows the presence of two distinct water masses: the fresher Atlantic water in the east and the more saline Mediterranean water in the west. (b) Temperature and (c) Absolute Salinity across the Almeria-Oran front. Isopycnals located below the summer thermocline slope downward to the east. Exact locations of the EcoCTD profiles are indicated (black triangles).

space, this DCM is composed of two different density classes: on the dense side of the front (west), the DCM mostly coincides with the $27.5 \mathrm{~kg} \mathrm{~m}^{-3}$ isopycnal, while on the light side of the front, the DCM tends to follow the $27 \mathrm{~kg} \mathrm{~m}^{-3}$ isopycnal (Fig. 10a). As one would expect, both oxygen supersaturation and elevated backscatter are seen over the DCM (Figs. 10b,c).

Beneath the DCM, an along-isopycnal filament of elevated backscatter is clearly visible between 27.5 and $28.5 \mathrm{~kg} \mathrm{~m}^{-3}$. This anomaly in particle concentration coincides with positive anomalies in both chlorophyll and oxygen saturation. This provides evidence of the presence of a subducted filament advecting water from the DCM to a depth of up $150 \mathrm{~m}$ that would be difficult to diagnose using hydrographic variables alone. The relatively weak correlation of backscatter with chlorophyll and dissolved oxygen suggests that the observed filament has been subducted for a long enough time period that the organic material it contains is no longer fluorescing, or that it carries nonbiological material. Biological time scales can theoretically be used to estimate the age of the subducted filament. Efforts to characterize subduction pathways and time scales are underway and will be presented in a subsequent study.

\section{Summary and technical improvements}

The EcoCTD builds on the well-established UCTD system, for which a robust mode of operation and data processing have been developed (Rudnick and Klinke 2007; Ullman and Hebert 2014). The EcoCTD augments the traditional temperature and conductivity measurements
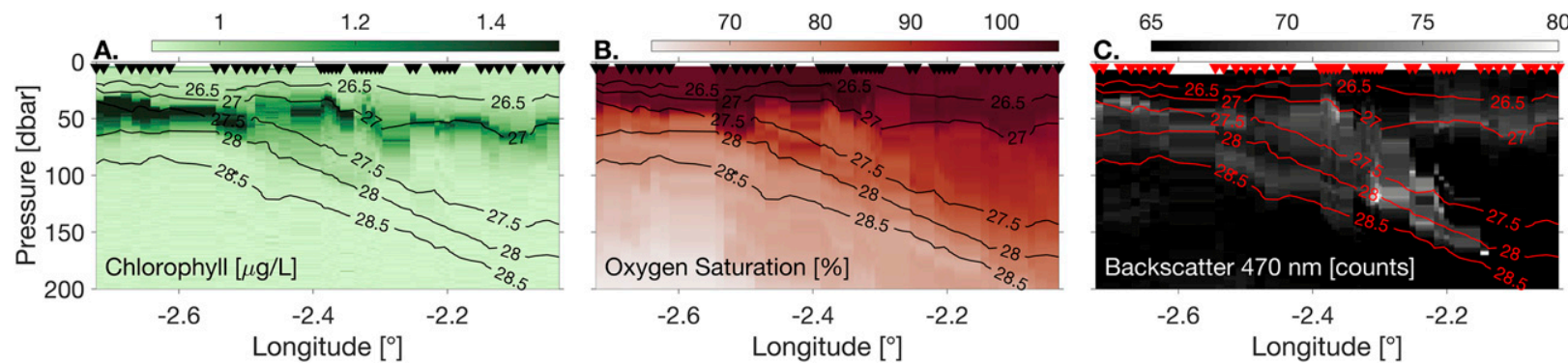

FIG. 10. Transects of (a) chlorophyll, (b) oxygen saturation, and (c) backscatter across the Almeria-Oran front as observed by the EcoCTD. 
TABLE A1. List of parameters necessary to simulate the underwater trajectory of the EcoCTD in ProteusDS.

\begin{tabular}{lcc}
\hline \multicolumn{1}{c}{ Parameter name } & Value & Source \\
\hline EcoCTD & & Measured in the laboratory \\
Length & $0.9 \mathrm{~m}$ & Measured in the laboratory \\
Diameter & $0.152 \mathrm{~m}$ & Measured in the laboratory \\
Buoyancy & $44.145 \mathrm{~N}$ & Measured in the laboratory \\
Mass (dry) & $12.49 \mathrm{~kg}$ & Fitted parameter \\
Normal drag coefficient & 1.2 & Fitted parameter \\
Tangential drag coefficient & 0.021 & Fitted parameter \\
Added mass coefficient & 4.0 & Fitted parameter \\
Line & & Fitted parameter \\
Normal drag coefficient & 1.5 & Fitted parameter \\
Tangential drag coefficient & 0.021 & Manufacturer \\
Added mass coefficient & 1.0 & Manufacturer \\
Axial stiffness & $3.71 \times 10^{4} \mathrm{~N}$ & Manufacturer \\
Diameter & $1.4 \times 10^{-3} \mathrm{~m}$ & Ship GPS \\
Specific gravity & 0.9 & Field testing \\
Ship/winch & & Profile specific \\
Ship velocity & $1.57 \mathrm{~m} \mathrm{~s} \mathrm{~s}^{-1}$ & \\
Winch pay-in rate & & \\
\hline
\end{tabular}

with concurrent fluorescence, backscatter, and oxygen data. Cross validation with shipboard CTD data demonstrates the quality of the data collected by the EcoCTD. The EcoCTD provides profiles at high temporal $(\sim 5 \mathrm{~min})$ and spatial $(\sim 1 \mathrm{~km})$ resolutions. A postprocessing analysis was carefully developed to account for response lags resulting from the different inherent response times of individual sensors, as well as advective lags, emerging from the design of the EcoCTD. The EcoCTD presents several operational advantages compared to equivalent underway platforms: 1) it provides both physical and bio-optical measurements, 2 ) it is lightweight and versatile, making the EcoCTD easy to deploy and recover, with little impact on the ship's course and cruising speed, and 3) it relies on the lightweight UCTD winch, which is highly adaptable to operational constraints (e.g., ship size, power requirements). Finally, an analysis of preliminary data revealed that bio-optical data collected from the ECOPuck can be used on both the downcast and upcast during a profile. A dynamical model is used to resolve the underwater trajectory of the EcoCTD on the upcast, allowing for better geolocalization of the observations than a simple linear model would. Some limitations inherent to the design of the EcoCTD and its mode of operation still remain: 1) operating the EcoCTD winch requires one to two people at all time, which is constrained by weather and wave conditions, 2) the probability of instrument loss is more than the UCTD probe, due to the higher weight and increased line tension, and 3) data are only available upon recovery (i.e., near-real-time data).

Following the 2018 field campaign, a series of technical improvements were implemented in a second version of the EcoCTD. The oxygen sensor (Rinko III) was replaced by a different fast response oxygen sensor (RBR Coda ODO), which also allows for logging of the temperature signal as measured by the oxygen sensor. Having access to the temperature record from the oxygen sensor will not only provide a backup in case of a CTD failure, but also allows for more robust alignment between the CTD and oxygen sensors. In addition, the second version of the EcoCTD includes a connectorized end cap with a cable running from the RBR logger to the top of the EcoCTD. Data are thus available for download through a cabled connection without disassembly, allowing for a faster download and reduced battery usage in comparison to data download through Wi-Fi. Other technical improvements are under development, such as an emergency recovery for situations when the winch line ruptures. This system aims at allowing probe recovery before permanent damage or loss of sensors in order to limit operational costs and the environmental footprint.

Acknowledgments. Authors would like to acknowledge Melissa Omand, Ben Pietro, and Jing He for their valuable input during the design phase of the EcoCTD, as well as for their support for deploying the EcoCTD in the field. We are grateful to Eva Alou, Andrea Carbonero, and John Allen for providing calibrated data from the shipboard CTD. Authors would also like to thank Don Peters along with Dynamics System Analysis Ltd. for facilitating access to ProteusDS and providing support in using the software. We are grateful to the crew of the RV Armstrong and NRV Alliance for their support in the field. Development of the EcoCTD is 

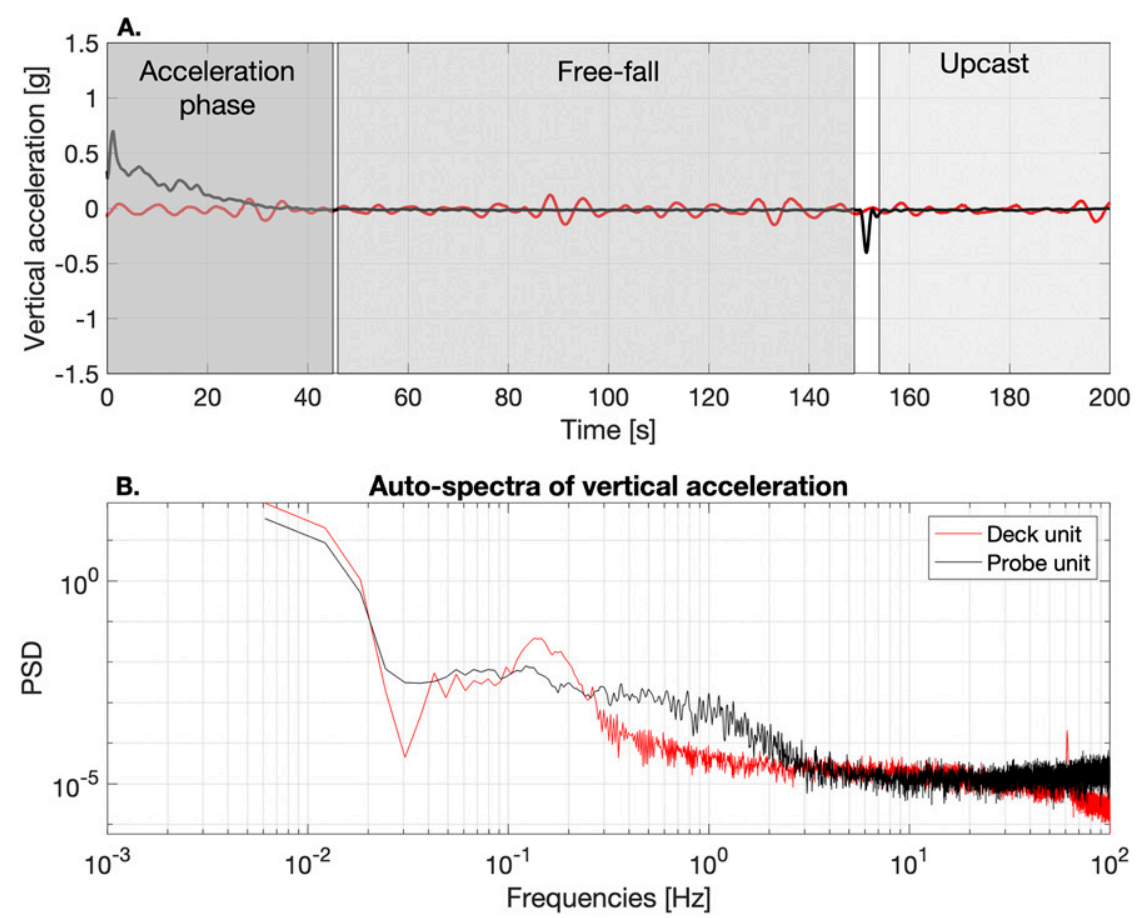

FIG. B1. (a) Vertical acceleration (positive downward) as recorded by inertial measurement units (IMUs) located on the ship's working deck (red), as well as mounted in the EcoCTD (black). (b) Autospectra of both IMUs for that particular downcast (0-150 s). Four different phases are highlighted in (a): 1) the acceleration phase, where the EcoCTD reaches terminal velocity $(0-45 \mathrm{~s})$; the free-fall phase, where acceleration is constant and close to zero (i.e., constant fall rate; $45-150 \mathrm{~s}$ ); 3 ) the breaking phase, characterized by a sharp negative peak corresponding to the winch operator activating the break (150-155 s); and the upcast (only first $45 \mathrm{~s}$ are shown).

supported by the Office of Naval Research (ONR) through the CALYPSO Departmental Research Initiative (Grant N000141613130). Advanced field testing was supported by Woods Hole Oceanographic Institution internal funding. MATLAB routines for data processing are publicly available at https://github.com/mfreilich1/ ecoctd_processing.

\section{APPENDIX A}

\section{Dynamical Line Model: ProteusDS}

ProteusDS is a software package developed by DSA that can be used to test virtual setups of many marine installations and technologies (moorings, pipelines, fish farms, towed bodies, etc.). It relies on a variety of advanced hydrodynamic and finite-element analysis techniques that are described in detail in DSA (2018). Other software packages capable of modeling line dynamics, both licensed and open-source, could be used to solve the equations of motions describing the EcoCTD's behavior (e.g., MoorDyn; Hall and Goupee 2015).
Table A1 lists the parameters required by ProteusDS to compute the EcoCTD's trajectory. While some quantities were provided by the manufacturer or directly determined in the laboratory (e.g., dimensions, buoyancy), other parameters were tuned to match the observed EcoCTD dynamics. These specific parameters (e.g., drags) were determined by maximizing the match between simulated results and observations, using different features of a profile. The simulation of the downcast allowed for the determination of the axial drag parameter for the EcoCTD, the tangential drag coefficient of the line, and the added mass of the EcoCTD. A downcast can be separated into two phases: A rapid initial acceleration from rest to a peak velocity (0-10 s; see Fig. 2), and a slow deceleration as pressure increases due to more line penetrating the water (10-80 s; see Fig. 2). The acceleration phase was used to tune the added mass of the EcoCTD. Added mass coefficient values for similarly shaped objects are typically around 1.0, however, when this value is used in the simulation, the probe accelerates much quicker than in the experiment. This is thought to be caused by 
winch inertial effects that are not accounted for in the simulation. The added mass coefficient for the probe was thus increased in the simulation to represent the winch inertia in the system. The peak velocity between the first and second phase of the downcast is assumed to be a function of the EcoCTD axial drag only, as the peak velocity is reached in the first $10 \mathrm{~s}$, when little line has entered the water. The rate of deceleration during the second phase, on the other hand, is assumed to be a function of the line tangential drag only. The line tangential drag is then adjusted to match the deceleration of the EcoCTD through the downcast. Generic values were used to set the normal drag of the line and the EcoCTD, as well as the added mass of the line. Finally, the pay-in rate of the winch is assumed to be constant and the averaged value over a cast is used. In reality, the pay-in rate is time dependent, increasing as more line is spooled onto the winch's drum. The empirical value used in this study was determined by processing frames from a video recording of the winch over several profiles.

\section{APPENDIX B}

\section{Evidence for Decoupling of Ship and EcoCTD Motions}

To obtain good-quality data, it is important for the EcoCTD to be free-falling. Free-falling removes error associated with the "looping effect," where the ship's heaving due to waves pulls on the profiler and generates a short-lived negative fall rate. Maintaining a sufficient, positive, fall rate is also important to ensure water within the inductive conductivity cell is properly flushed out. In the case of the UCTD, this was addressed by spooling line onto the UCTD's tail spool: when the ship is heaving up, it unspools line off the tail spool instead of pulling the UCTD probe upward (Rudnick and Klinke 2007).

For the EcoCTD, no line is spooled onto the tail spool. To confirm that the EcoCTD remains in free-fall during the downcast and is fully decoupled from the ship, two inertial motion units (IMUs) were mounted; one on the deck of the ship next to the winch, and another in the EcoCTD housing. Time series of vertical acceleration were extracted from each IMU to quantify the covariance between the two units (Fig. B1). During a typical profile, the EcoCTD first goes through an initial accelerating phase before reaching terminal velocity for the remainder of the profile, which is characterized by a vertical acceleration of $0 \mathrm{~g}$ (Fig. B1a). The time series of vertical acceleration measured by the deck IMU shows a sinusoidal pattern emerging from the ship's movement due to the waves recorded at $3-5 \mathrm{~m}$ significant wave height on the sampling day. This periodic behavior is picked up in the autospectrum of the vertical acceleration from the deck-mounted IMU, with a broad peak between 0.09 and $0.3 \mathrm{~Hz}$, corresponding to a period ranging from 11 to $3 \mathrm{~s}$ (Fig. B1b). This peak is absent from the autospectrum of the IMU mounted into the EcoCTD, supporting the conclusion that the EcoCTD is indeed free-falling while profiling, even in 3-5 $\mathrm{m}$ waves when ship heave is significant.

\section{REFERENCES}

Allen, J., D. A. Smeed, J. Tintoré, and S. Ruiz, 2001: Mesoscale subduction at the Almeria-Oran front: Part I: Ageostrophic flow. J. Mar. Syst., 30, 263-285, https://doi.org/10.1016/S09247963(01)00062-8.

Alou, E., A. Cabornero, and J. Allen, 2018a: NRV Alliance report on delayed mode calibration of chlorophyll data CALYPSO trials cruise. SOCIB Tech. Rep., 8 pp.

,-- , and,$- 2018 \mathrm{~b}$ : NRV Alliance report on delayed mode calibration of dissolved oxygen data CALYPSO trials cruise. SOCIB Tech. Rep., 10 pp.

Barth, J. A., R. T. O'Malley, J. Fleischbein, R. L. Smith, and A. Huyer, 1996: SeaSoar and CTD observations during coastal jet separation cruise W9408A, August to September 1994. Oregon State University College of Oceanic and Atmospheric Sciences Tech. Rep. 162, 170 pp., https://ir.library.oregonstate.edu/concern/ defaults/fj236371s.

Bittig, H. C., B. Fiedler, R. Scholz, G. Krahmann, and A. Körtzinger, 2014: Time response of oxygen optodes on profiling platforms and its dependence on flow speed and temperature. Limnol. Oceanogr.: Methods, 12, 617-636, https://doi.org/10.4319/ lom.2014.12.617.

Briggs, N., M. J. Perry, I. Cetinić, C. Lee, E. D’Asaro, A. M. Gray, and E. Rehm, 2011: High-resolution observations of aggregate flux during a sub-polar North Atlantic spring bloom. Deep-Sea Res. I, 58, 1031-1039, https://doi.org/10.1016/j.dsr.2011.07.007.

Brown, J., K. Brander, L. Fernand, and A. Hill, 1997: Scanfish: High performance towed undulator. Oceanogr. Lit. Rev., 44, 523.

D'Asaro, E., C. Lee, L. Rainville, R. Harcourt, and L. Thomas, 2011: Enhanced turbulence and energy dissipation at ocean fronts. Science, 332, 318-322, https://doi.org/10.1126/science.1201515.

Dever, M., M. Freilich, B. Hodges, T. Farrar, T. Lanagan, and A. Mahadevan, 2019: UCTD and EcoCTD observations from the CALYPSO pilot experiment 2018: Cruise and data report. WHOI Tech. Rep. WHOI-2019-01, 43 pp., https:// hdl.handle.net/1912/23637.

DSA, 2018: ProteusDS v2.45 manual. Dynamic Systems Analysis Ltd. Rep., 367 pp.

Furlong, A., J. Osler, H. Christian, D. Cunningham, and S. Pecknold, 2006: The Moving Vessel Profiler (MVP)—A rapid environmental assessment tool for the collection of water column profiles and sediment classification. Defense Research and Development Canada Tech. Rep., 13 pp., https://apps.dtic.mil/dtic/tr/fulltext/u2/ 1005165.pdf.

Hall, M., and A. Goupee, 2015: Validation of a lumped-mass mooring line model with DeepCwind semisubmersible model test data. Ocean Eng., 104, 590-603, https://doi.org/10.1016/ j.oceaneng.2015.05.035. 
Halverson, M., and Coauthors, 2017: Guidelines for processing RBR CTD profiles. Fisheries and Oceans Canada Tech. Rep., $45 \mathrm{pp}$.

Jones, B. H., C. M. Lee, G. Toro-Farmer, E. S. Boss, M. C. Gregg, and C. L. Villanoy, 2011: Tidally driven exchange in an archipelago strait: Biological and optical responses. Oceanography, 24 (1), 142-155, https://doi.org/10.5670/ OCEANOG.2011.11.

Mahadevan, A., 2016: The impact of submesoscale physics on primary productivity of plankton. Annu. Rev. Mar. Sci., 8 , 161-184, https://doi.org/10.1146/annurev-marine-010814015912.

McWilliams, J. C., 2019: A survey of submesoscale currents. Geosci. Lett., 6, 3, https://doi.org/10.1186/s40562-019-0133-3.

Omand, M. M., E. A. D'Asaro, C. M. Lee, M. J. Perry, N. Briggs, I. Cetini, and A. Mahadevan, 2015: Eddy-driven subduction exports particulate organic carbon from the spring bloom. Science, 348, 222-225, https://doi.org/10.1126/science.1260062.

Pinkel, R., M. Buijsman, and J. M. Klymak, 2012: Breaking topographic lee waves in a tidal channel in Luzon Strait. Oceanography, 25 (2), 160-165, https://doi.org/10.5670/oceanog.2012.51.

Pollard, R., 1986: Frontal surveys with a towed profiling conductivity/temperature/depth measurement package (SeaSoar). Nature, 323, 433-435, https://doi.org/10.1038/323433a0.
Rajagopalan, V., 2019: Optimization of the FastCTD ocean profiler from onboard data and computational modeling. University of California, San Diego, Rep., 85 pp.

Roman, C., D. S. Ullman, D. Hebert, and S. Licht, 2019: The Wire Flyer towed profiling system. J. Atmos. Oceanic Technol., 36, 161-182, https://doi.org/10.1175/JTECH-D-17-0180.1.

Rudnick, D. L., and J. Klinke, 2007: The underway conductivitytemperature-depth instrument. J. Atmos. Oceanic Technol., 24, 1910-1923, https://doi.org/10.1175/JTECH2100.1.

Ruiz, S., A. Pascual, B. Garau, I. Pujol, and J. Tintoré, 2009: Vertical motion in the upper ocean from glider and altimetry data. Geophys. Res. Lett., 36, L14607, https://doi.org/10.1029/ 2009GL038569.

— mesoscale frontal processes on the vertical transport of phytoplankton. J. Geophys. Res. Oceans, 124, 5999-6014, https:// doi.org/10.1029/2019JC015034.

Shroyer, E. L., and Coauthors, 2019: Upper layer thermohaline structure of the Bay of Bengal during the 2013 northeast monsoon. Deep-Sea Res. II, 172, 104630, https://doi.org/ 10.1016/j.dsr2.2019.07.018.

Ullman, D. S., and D. Hebert, 2014: Processing of underway CTD data. J. Atmos. Oceanic Technol., 31, 984-998, https://doi.org/ 10.1175/JTECH-D-13-00200.1. 